\title{
Seeking Identity through Landscape------the Politics of Land in Solar Storms
}

\author{
Wenjie Zeng \\ Nanchang Institute of Science \&Technology, Nanchang, Jiangxi, 330108
}

Keywords: solar storms, Angela, identity, landscape

\begin{abstract}
Solar Storms is the story of seventeen-year-old Angela Jensen's search for her birth family and her identity. The main character in this novel works to discover what it is to be human and how to live in harmony with the landscape. In this sense, finding home means finding the self in the great intelligence. It is through the knowledge and connection to the landscape around and within her that Angela reaches a sense of completion to her identity quests.
\end{abstract}

\section{Introduction}

Solar Storms begins when seventeen-year-old Angela Jensen returns to Adam's Rib after twelve years, her birthplace and the home of her grandmothers. Angela bears the scars of her mother Hannah's abuse, both physically and psychologically. It is those three nice women, Angela's great-great-grandmother Dora-Rouge, her great grandmother Agnes Iron, and her grandfather's abandoned first wife, a mother-like figure Bush that offer her love and protection. She firstly attains her identity through these women, therefore she is no longer a rootless teenager; just like "water going back to itself. I was water falling into a lake and these women were that lake.”(55)

Three major events prop up the structure of the novel --- the four women's journey to Fat-Island, the death of Hannah and the fight against white men's desire to build the dam. Each part stands for thawing, healing and recovering of Angela's scar. Landscape is a defining element in Native American's writing, which can be set as cultural identity or turning point. In Solar Storms, landscape is the accompaniment for Angela to find her cultural identity. The thesis is trying to figure out how the crucial element landscape works in Solar Storms through the three major events in the novel and the mutual reliance between Native Americans and landscape.

\section{The "thawing" Part}

In the "thawing" part, landscape is both the setting and metaphor in shaping characters' transformation. Four generations of women go beyond external and internal borders in order to complete their quest. The journey to Fat Island for these women, Dora Rouge, who initiates the trip with her desire to return to her home in the far north, has already begun to travel her life in a closed circle and step over the boundaries of this world to the next. Bush is summoned by water and decides to see what is happening with the white men's dam and help people suffered by the threatening of flood. Agnes is reluctant to send her mother to death in her mother's homeland, but she has no way out. For Angela, it is the water, flowers, mountains, and even mosquitoes that build her bond with nature and recover a connection to the earth. The journey of inner healing brings her home to fulfill the identity quest, a quest that can only be fully realized in community and bond with family members and the natural world.

During the journey, Dora Rouge sees and reads things that couldn't be seen by others. Bush "opened like the lilies that flowered on some of the islands," (176) the betrayals, the wounds and the solitudes are all gone. Agnes died elegantly and placidly, and feed her body to birds and wolves as she wishes. Angela does so much with her fellow travelers to find a home in Adam's Rib, and she finally finds a path towards home and wholeness by participation in the actual traumatic journey.

Once their journey is under way, "The four of us became like one animal," she explains. "We heard inside each other in a tribal way. I understood this at once and was easy with it. With my 
grandmothers there was no such thing as loneliness. Before, my life had been without all its ears, eyes, without all its knowing. Now we, the four of us, had the same eyes” (177). Being united as one, the four women act like salmons who are trying to return to their birthplaces. It is a journey of renewal, healing and transformation. In addition to achieving identification with the other women, Angela finds herself merging with the natural world. Stepping outside of time into a landscape, she begins to experience the immediacy of the water and land and to feel at home in the midst of her journey.

In this novel, mapping is cast as a type of scarring on the face of the landscape. As Bush attempts to prepare for a trip north, she laughs at the inadequate European maps. Angela says, "What I liked was that land refused to be shaped by the makers of maps" (123). The land is imagined here as possessing a will rather than a passive site; while maps perform a type of violence inflict on the land by the white people. "Land had its own will. The earth has more than one dimension. The one we see is only the first layer."(123). Besides the map imposed by white men, there is a map in the blood that brings Native Americans together as wholeness. In their eyes, landscape has spirit itself, offering love and protection to Native Americans, and they can understand each others' language.

"Everything had changed. We'd gone too far to turn back. Not too far in distance alone, but too far inside ourselves. No longer were we the women who left Adam's Rib, [...] now our arms were strong and we were articulate in the languages of land, water, animal, even in the harder languages of each other."(193) safely travelling that land, signals reclamation of identity in a natural world and healing for those individuals' suffering of isolation and dislocation. After the journey, they are no longer who they were.

\section{The "healing" Part}

“Any path between us had long since been closed."(230) that was the remark Angela made on Hannah. But upon hearing her death, she arrived at Hannah's house, which "looked from afar like a cigarette burn on the face of the world" (247). Undoubtedly, this image reminds her of the torture in her childhood. However, while she observes the interior of Hannah's house, it is almost empty. The emptiness of the house signifies the fragility and harmless of the present Hannah. Hannah is no longer the frightening image.

When Hannah dies soon after Angela visits her, however, her body becomes a different kind of landscape. As Angela and Bush begin to prepare Hannah for burial, Angela observes, "I looked for the first time at my mother's body, her arms so like mine, her bones familiar. She was covered with scars.” (252) actually, they are just like each other, even for the scars; there is no denying the blood relation. As Bush once said, "your mother was a skin that others wore."(77) Her body no longer belongs to herself, it is a place ready to be conquered, and it also serves as the symbol of violence against Native Americans. Just as the scene of Angela at Hannah's doorstep represented a shift, so does Hannah's body becomes a psychological threshold to Angela's healing. Hannah is much like the landscape around and inside her house; just as the house looks to Angel like a cigarette burn that reminds the torture, so Hannah's scars suggest that she has been abused too. Represented thus as both person and landscape, Hannah becomes a site where healing may be realized.

"Her desperation and loneliness was my beginning. Hannah had been my poison, my life, my sweetness and pain, my beauty and homeliness. And when she died, I knew that I had survived in the best of ways for I was filled with grief and compassion.”(251) Angela recognizes that her mother's beginning is also her beginning, and she may leave something permanently behind her, that is hatred and humiliation. After Hannah's death, Angela achieves a sense of maturity which can be represented in two events: taking care of her baby sister Aurora and assuming the responsibility to keep her tribal alive.

In this part, Hannah is just like the landscape with no foundation, where memories of past injustice and future hope meet, where the cultural identity has been defined. The scars she left to Angela, no matter Angela wants or not, can not be erased. It is not until Angela saw Hannah's dying body, can she fully got healed. And the relationship Angela develops with Hannah becomes an important step in healing her childhood physical and psychological hurt. The scar can also be seen 
as a symbol of devastation white people inflict upon the Native Americans, and the healing is also crucial to Angela's emerging sense of political action.

The author develops empathy through a sense of place as represented in the houses, bodies, and landscapes that her characters inhabit. In terms of the narrative as a whole, images of interior houses and bodies on the one hand, and in exterior landscapes on the other, serve as sites where the reader can find a more defined sense of identity to emerge. And it paves the way for the Angela's growing sense of tribal identity.

\section{The "recovering" Part}

In the "recovering" part, after Angela finds her identity through the family members, she spares no effort to stop the rerouting of the rivers that will flood lands and villages. "Families belonged to clans, and it was by clan that the human being joined with the animal and plant world."(505) the desire to fight for their lands together establishes Angela and the members of this community a new relationship, she explains, "We had pride. We were in something together. We no longer allowed others to call us Fat-Eaters. We were again the Beautiful People." (313). In the process of resistance, Angela, once wounded and scarred, stands strong and speaks in the name of those who cannot speak for themselves. Here, landscape plays a part of turning point, which drives the story toward the climax.

"Between us, there had once been a bond, something like the ancient pact land had made with water, or the agreement humans once made with animals. But like those bonds, this bond, too, lay broken" (22). The broken of the bond suggests that white people have exploited the lands of her tribe, animals, and people. "The island meant much to me because of the stories told about it and my ancestors who went there and what befell them."(265) Angela’s acceptance of Native American world views characterizes her maturity to appreciate her cultural legacy. Angela, along with the larger community, establishes a common purpose--- fight for the waters and land, which ensures a way of cohesiveness. Individual identity is thus not just grounded in tradition, not merely located in landscape; it holds itself responsible to a larger community.

The specific process of the dam projects also shapes the emotional, political and spiritual journey of Angela. Angela's actions are mostly taken in two ways: one is an intimation of myth when she acts like wolverine to sneak into the white people's store to steal food; the other is her protest about the injustices against Native Americans and the exploitative industry's threat to their homelands in radio program "Indian Time." Although both are not so successful, her fight for her people and tribal lands can be seen as the result of her successful re-entry into the legacy of her culture.

"This sense of identity was intimately linked with the surrounding terrain, to the landscape which has often played a significant role in a story or in the outcome of a conflict.”(Silko 508) Unlike white people, the Native Americans have always been unwilling to relinquish their land for dams or highways; they believe the landscape could not be improved upon. So the white men's decision to build the dam has had a powerful psychological impact upon the Native people. Actually the fighting for landscape brings them into wholeness; they reassure individual identity and reaffirm cherished values of the tribal through the struggle. "The earth loves our people. Even in a hard place. The water loves us. We live in the place of its birth. This is where rivers are born and we are going to protect them.”(306)

Although their struggle proves to be futile, Angela has learned to embrace mysteries, restore the interconnectedness between human and nature, and look for and protect ancestral markers. "Old creatures are remembered in the blood. Inside ourselves we are not yet upright walkers. We are tree. We are frog in amber. Maybe earth itself is just now starting to form.”(351) the ending of the story is peaceful and promising, and we can also find the strength underneath the still water.

\section{Conclusions}

Solar Storms actually is Angela's identity-seeking through interior and exterior journeys, it is both a personal and communal journey. During this journey, Angela realizes that the destruction of 
her tribal lands, the broken bonds among her family members, and her separation from her mother are results of the imbalance caused by the interference of the white people with her tribe's culture. Landscape shapes the journey of transformation, and Angela's scarring face also can be considered as a landscape from distorted to normal. As Bush said "Some people see scars and it is wounding they remember. To me they are proof of the fact that there is healing" (125).

Near the end of Solar Storms, Angela reflects on what she has learned and how she has grown during her experiences in the fighting of the government's dam building. She becomes, like the land, defiant. She describes her admiration for the land and "its mischief and trickiness [. . .] its wildness, its stubborn passion to remain outside their sense of order" (123). The transformation of an exiled teenager to a "defiant land" lies in the reunion with the land and the cultural traditions that celebrate the organic relationship between human and the landscape.

The author juxtaposes the healing powers of the landscape with the protagonist's fighting for a healing of the landscape. It is both through their return to the tribal territories and their activism for the protection of the tribal lands that Angela reaches a sense of completion to her identity quests. Hogan's representations of landscape in Solar Storms, in motivating readers to recognize empathetic connections between landscapes and humans, and opens the possibility for readers to be familiar with and accept the concept of landscape in Native Americans' view; moreover, it indulges the readers in the exotic presence of landscape.

\section{References}

[1] Silko, Lesley Mamon. "Landscape, History, and the Pueblo Imagination.” The Woman That I Am: The Literature and Culture of Contemporary Women of Color. Ed. D. Soyni Madison. New York: St. Martin’s, 1994.

[2] Hogan, Linda. Solar Storms. New York, W. W. Norton, 1997.

[3] Hogan, Linda. "First People." Intimate Nature: The Bond Between Women and Animals. Eds. Linda Hogan, Deena Metzget, and Brenda Peterson. New York: Fawcett Columbine, 1998: 6-19

[4] Nelson, Robert. Place and Vision: The Function of Landscape in Native American Fiction. New York: Peter Lang, 1993.

[5] Schweninger, Lee. Listening to the Land, Native American Literary Responses to the Landscape. Athens, Georgia: U of Georgia P, 2008. 